\title{
Coordenação no mercado do café brasileiro: o desserviço da classificação por defeitos
}

\section{Coordination in the Brazilian green coffee market: the disservice of the classification by defects}

\author{
Fabio Lyrio Santos ${ }^{1}$ \\ José Flávio Diniz Nantes²
}

\begin{abstract}
Resumo: O mercado do café brasileiro é coordenado por um mecanismo regulatório responsável pela padronização e classificação oficial dos lotes da produção nacional. O cerne do sistema de classificação são os deméritos das amostras, o que desprestigia a qualidade intrínseca dos cafés comercializados e compromete seu desempenho em preço. Este artigo apresenta resultados de uma pesquisa que estudou a tríplice inter-relação entre o sistema de classificação do café, os atributos de qualidade requeridos pela indústria e a remuneração do produto ao cafeicultor. Treze agentes da cadeia produtiva foram investigados: cinco cooperativas das principais regiões cafeeiras do país, cinco torrefadoras a elas associadas e três empresas intermediárias (traders) da região de Hamburgo, na Alemanha. Os resultados atestam a necessidade de intervenção na coordenação do mercado e revelam estratégias já implantadas pelo setor produtivo capazes de evidenciar melhor a qualidade dos lotes nas negociações, orientar melhor o sistema de pagamento e criar condições para melhor desempenho em preço do produto no mercado internacional.

Palavras-chave: Agronegócio café. Sistema de classificação. Governança. Pagamento por qualidade.
\end{abstract}

\begin{abstract}
The Brazilian green coffee market is coordinated by a regulatory mechanism responsible for the official standardization and classification of the national production. The core of the classification system is a sample demerit index, which depreciates the intrinsic quality of traded coffees and affects their market performance. This paper presents the results of a research which studied the triple inter-relationship between the classification system, the quality attributes required by industry, and the product payment. Thirteen supply chain agents were investigated: five coffee cooperatives from Brazil's main producing regions, five roasting companies linked to them, and three intermediary companies (traders) from the region of Hamburg, Germany. The results confirm the need for intervention in the market coordination. They also reveal strategies already implemented by the productive sector that are able to evince the quality of batches during negotiation, better guide the payment system, and create conditions for a better product price performance in the international market.
\end{abstract}

Keywords: Coffee business. Classification system. Governance. Payment for quality.

\section{Introdução}

O café é uma das mais importantes commodities agrícolas do mercado internacional. A produção mundial da cultura é liderada pelo Brasil desde a década de 1850 . No país, a coordenação do mercado interno cabe a uma normativa governamental que estabelece os padrões classificatórios para o produto, toda a terminologia pertinente e as considerações acerca da inserção dos lotes no mercado. Essa normativa define as características de identidade e de qualidade para a classificação oficial do produto em seu estado beneficiado grão cru. O resultado do processo classificatório, por sua vez, orienta a precificação dos cafés da produção nacional e, consequentemente, a remuneração de cafeicultores, cooperativas e exportadores.

As diretrizes e o reflexo no mercado dessa sistemática de classificação foram objeto deste estudo. A questão abordada pela pesquisa refere-se à responsabilidade do sistema, enquanto mecanismo coordenador do mercado interno, com relação à orientação de preços para a remuneração do setor produtivo.

O mecanismo que regulamenta a classificação do café brasileiro consta no anexo da Instrução

\footnotetext{
${ }^{1}$ Instituto Federal do Espírito Santo - IFES, Campus Itapina, Rodovia BR-259, km 70, CEP 29.709-910, Colatina, ES, Brasil, e-mail: fabio.santos@ifes.edu.br

2 Departamento de Engenharia de Produção, Universidade Federal de São Carlos - UFSCar, Rodovia Washington Luís, km 235, CEP 13.565-905, São Carlos, SP, Brasil, e-mail: fnantes@ufscar.br
}

Recebido em 30/1/2013 — Aceito em 20/3/2014

Suporte financeiro: Coordenação de Aperfeiçoamento de Pessoal de Nível Superior (CAPES) e Deutscher Akademischer Austauschdienst (DAAD). 
Normativa n. 8, de 11 de junho de 2003, do Ministério da Agricultura, Pecuária e Abastecimento (MAPA). Em seu bojo, a atual regulamentação pouco alterou a estrutura classificatória das legislações anteriores. Mas, apesar de bastante solidificado, o sistema vigente é falho e ineficiente, sendo questionado pelo próprio setor.

O fator negativo preponderante é sua tipologia longeva baseada nos defeitos físicos do lote. O produto oficialmente classificado é posto no mercado com pouca evidência de suas características intrínsecas, em lotes identificados por descrições comerciais ruins, do ponto de vista mercadológico. Isso impede que o comprador perceba determinados atributos de qualidade do lote negociado, o que se reflete numa prática oportunística de preços no mercado interno, certo desprezo ou desconhecimento do mercado externo a respeito da real qualidade do café brasileiro, além de comprometer a ação de políticas baseadas em diversificação.

A classificação por defeitos também desserve o setor industrial quanto à eficácia na seleção da matéria-prima. $\mathrm{O}$ sistema dificulta à indústria, no momento da compra, certificar se o produto adquirido atende a determinados requisitos de qualidade, o que alimenta a incerteza nas transações.

Este artigo apresenta resultados de uma pesquisa cujo objetivo foi estudar o processo de comercialização do café beneficiado brasileiro, analisando a tríplice inter-relação entre o sistema de classificação, os atributos de qualidade requeridos pela indústria e a remuneração do produto ao cafeicultor. Os dados da pesquisa permitiram desenvolver uma proposta alternativa de classificação, baseada na demanda percebida do setor produtivo.

Neste momento, são apresentadas e discutidas as evidências empíricas acerca do problema, da observação de como o sistema de remuneração deste mercado está orientado e das implicações nos macrossegmentos de produção e de industrialização, incluindo o elo de intermediação entre ambos. Tais implicações foram constatadas por meio da análise das transações interfirmas, das estratégias adotadas pelos setores para lidar ou contornar o problema e do desempenho em preço dos lotes comercializados oficialmente classificados. Entende-se que a proposta de classificação desenvolvida deva ser discutida em trabalho futuro, permitindo uma explanação que acrescente os resultados de seu teste de validação.

Convém observar que as menções ao produto café beneficiado, ou, às vezes, apenas café, neste estudo, referem-se à denominação comercial do grão cru do cafeeiro (Coffea sp.), obtido por secagem do fruto, destinado como matéria-prima à indústria de torrefação. No mercado internacional, o café beneficiado é denominado café verde (green coffee), termo que não deve ser confundido com o verde de não maduro. O beneficiamento, em questão, refere-se ao processamento mínimo do produto, realizado ainda no campo, permitindo seu armazenamento por período longo (BORÉM, 2008; MATIELLO, 1991).

\section{Governança nas transações do café brasileiro}

As formas de governança e orientação do sistema de pagamento nos setores agroindustriais podem ser estudadas a partir de várias frentes teóricas, tomando-se separadamente as relações intra e intersegmentos das cadeias produtivas. Tendo esta pesquisa o foco nas relações e nos mecanismos de coordenação horizontal empregados entre o segmento de produção e a indústria de transformação, o pensamento teórico alinha-se com o estudo neoinstitucionalista.

Sob esta óptica, um dos principais aportes é a vertente denominada Nova Economia Institucional (NEI). Esta vertente originou-se, basicamente, do institucionalismo da escolha racional, escola de pensamento assim definida por Hall e Taylor (1996), que evidencia a análise racional de ganho nos processos políticos e sociais. As ações dos agentes são estabelecidas mediante a consideração de pressupostos comportamentais e sua coordenação envolve fatores restritivos, como a assimetria de informação e os custos transacionais de mercado, e fatores institucionais, como a estrutura organizacional e os direitos de propriedade. Segundo a NEI, as relações interinstitucionais são estudadas a partir de duas abordagens: o ambiente institucional e os mecanismos de governança (MARCH; OLSE, 1993; MÍGUEZ, 2007; PETERS, 2005; SCOTT, 2001).

A aplicação da NEI aos setores agroindustriais foi analisada por Azevedo (2000). Segundo o autor, as particularidades do ambiente institucional, como as políticas de preços mínimos, os direitos de propriedade da terra, a reforma agrária e as políticas de segurança alimentar, são elementos condicionantes das ações dos agentes. Os arranjos institucionais, desse modo, exercem influência relevante sobre a eficiência e a competitividade das cadeias produtivas. Nesses setores, as estruturas de governança, os inter-relacionamentos e as características intrínsecas dos produtos definem com mais exatidão os mecanismos de coordenação, do que apenas o sistema de preços do mercado.

De acordo com Williamson (1985), as estruturas de governança são mecanismos econômicos construídos para reduzir a incerteza nas transações. No caso do café beneficiado, commodity cuja avaliação da qualidade envolve um número grande de atributos, parte significativa dessa incerteza advém da impossibilidade do comprador mensurar tais atributos, notadamente os de natureza intrínseca, no momento da negociação. O que delega ao sistema de classificação 
a responsabilidade de desvelar os valores envolvidos às partes negociantes.

Neste sentido, é útil recuperar alguns conceitos da teoria dos custos de mensuração (TCM), uma das importantes correntes oriundas da NEI. A TCM auxilia a entender as transações, mesmo as mais simples, como entidades que podem ser decompostas em dimensões. Em Barzel (1982), que pode ser considerada a obra mais elementar da TCM, o autor destaca a importância de verificar e medir os direitos de propriedade dos atributos dos ativos negociados em cada dimensão.

Nas negociações do café beneficiado entre indústria e setor produtivo é possível identificar várias dessas dimensões: nível de umidade do produto; método de secagem utilizado; quantidade de grãos pretos, verdes ou ardidos; sistema produtivo; tecnologia na pós-colheita; modo de armazenamento; uso de defensivos e fertilizantes químicos; além de uma série de outros atributos associados à produção orgânica, à sustentabilidade socioambiental e às características sensoriais da bebida.

Cada dimensão da transação envolve a troca de um direito de propriedade, representando, dessa forma, um determinado valor para os negociantes. Caso os direitos de propriedade não estejam devidamente definidos no ato da negociação, esse valor tende a ser, no todo ou em parte, dissipado (BARZEL, 1997, 2005; ZYLBERSZTAJN, 2005).

Esses autores explicam que a indefinição dos direitos de propriedade advém do fato dos custos de medir determinado atributo serem demasiadamente altos, podendo chegar ao ponto de inviabilizar sua contratação. As negociações, portanto, exigem uma coordenação amparada por estruturas minuciosas, caso contrário o produto de melhor qualidade tende a ser mal remunerado. Por outro lado, no caso de atributos que podem ser medidos a baixo custo, sua contratação ocorre sob esforço mínimo de coordenação.

Barzel (1995) mostra que se o comprador não consegue verificar os atributos desejáveis do produto no momento da compra, inevitavelmente está assumindo o risco de um comportamento oportunista pela contraparte. Segundo Zylbersztajn (2005), em negociações que envolvem pouca especificidade e produtos ofertados por um número muito grande de produtores, a governança pode ser obtida por meio do sistema de preços. No entanto, como o Brasil produz cafés de características bastante distintas, principalmente em função das diferenças regionais e dos processos empregados, o preço não é um mecanismo capaz de, isoladamente, exercer a governança do mercado. Daí a importância de um mecanismo coordenador auxiliar, papel que caberia ao sistema de classificação do produto cumprir.

\subsection{Modelo atual: a classificação por defeitos}

Os critérios utilizados pela normativa do MAPA para a classificação dos cafés produzidos no país distinguem o produto segundo: a espécie cultivada; o formato dos grãos e a granulometria; o aroma e o sabor; a bebida; a coloração dos grãos; e a qualidade (BRASIL, 2003).

$\mathrm{Na}$ prática, a base da classificação e, por conseguinte, da estrutura de coordenação do mercado interno, está apoiada em três indicadores principais: a espécie; a qualidade, que é representada por um indicador numérico denominado tipo; e a bebida. Os demais quesitos classificatórios são empregados em um número restrito de negociações. A classificação quanto à espécie, tipo e bebida acaba sendo, na maioria das vezes, a referência para a remuneração do setor produtivo.

De acordo com a espécie, o produto pode ser classificado em duas categorias: uma, à qual pertencem os cafés provenientes da espécie Coffea arabica e, a outra, à qual pertencem os cafés da espécie Coffea canephora. Praticamente todo o parque cafeeiro nacional é formado pelo cultivo dessas duas espécies, representadas, respectivamente, pelos cultivares denominados café arábica e café robusta. Nas áreas em que o café robusta é cultivado no Brasil, ele ficou mais conhecido como café conilon. De acordo com Ferrão et al. (2007), o termo é uma adaptação linguística do nome da variedade de $C$. canephora amplamente difundida nessas regiões, a kouilou.

Dentro de sua categoria o café beneficiado recebe uma descrição comercial pautada fundamentalmente no tipo e na bebida. Para a normativa, o tipo é o indicador da qualidade do café. Mas qualidade, segundo Toledo (2001), é uma propriedade que sintetiza múltiplos atributos do produto, podendo ser avaliada por meio de um conjunto de características e parâmetros específicos, intrínsecos ou associados ao produto. $\mathrm{O}$ indicador tipo, a rigor, apenas fornece ao negociante uma expectativa com relação à quantidade de defeitos físicos no lote em questão.

Por definição, constituem-se como defeitos físicos os grãos avariados ou não conformes, as impurezas e qualquer matéria estranha, encontrados nas amostras (300 gramas) levadas à classificação. O resultado da contagem dos defeitos físicos é comparado a uma escala de sete níveis, em que cada nível indica o tipo do café. Esta indicação é numérica, variando desde o tipo 2, o café menos defeituoso, até o tipo 8, o mais defeituoso.

De acordo com a bebida, a norma define sete subgrupos para os cafés do grupo arábica e quatro subgrupos para os cafés do grupo robusta. O indicador da bebida é obtido por meio do teste denominado prova da xícara. As nomenclaturas utilizadas por 
este indicador, no caso dos cafés do grupo arábica, foram herdadas de normatizações anteriores e são extremamente técnicas, sem praticamente nenhum estímulo do ponto de vista do apelo comercial de consumo: bebida estritamente mole; mole; apenas mole; dura; riada; rio ou rio zona. Martins (2008, p. 300), inclusive, as considera pífias.

Como não existia, nas regulamentações anteriores, classificação de bebida para os cafés do grupo robusta, houve mais atenção quanto aos termos utilizados pela norma atual para o indicador nesta espécie: bebida excelente, boa, regular ou anormal. Mas, na prática, a indicação da bebida em descrições comerciais de cafés robustas é rara. Exemplos de como o café brasileiro é descrito e comercializado nas principais praças de negociação do país podem ser vistos no Quadro 1.

No estudo sobre o sistema agroindustrial do café de Zylbersztajn, Farina e Santos (1993), os autores já haviam se atentado ao problema da ênfase nos defeitos dada pelo sistema de classificação do café, vigente na época. Duas décadas depois, e apesar da reedição da norma em 2003, o problema ainda se mostra pertinente. Os autores chegaram a sugerir que o tema fosse tratado em trabalhos futuros (p. 230). Porém, o debate sobre a questão na literatura parece não ter avançado, desde então.

\subsection{A evolução do marco regulatório}

O café é cultivado como atividade econômica no Brasil desde meados do século XVIII, quando já compunha a pauta de exportação do país. Nesse período, a única forma de especificar os cafés brasileiros nos mercados de destino era com relação aos portos de embarque: Café do Porto do Rio de Janeiro; Café do Porto da Bahia; e Café do Porto de Santos (MATIELLO, 1991).

Segundo este autor, a primeira referência sobre classificação brasileira para o café data de 1836. Em seis de março daquele ano, o então Presidente da Província do Rio de Janeiro, Paulino José Soares de Sousa (1807-1866), regulamentava a Lei
Provincial n. 33. Em seu Art. $7^{\circ}$, o texto dizia que o café passaria a ter três qualificações, baseadas tão somente na aparência física dos lotes: café de primeira sorte, categoria constituída pela presença de grãos chumbados, com algumas pintas ou quebras; café de segunda sorte, constituída de grãos muito desiguais ou esbranquiçados; e café escolha, categoria tolerante com a presença de matérias estranhas e grãos defeituosos. Essa categorização, porém, serviu apenas para orientar as notas de venda no país.

O primeiro dispositivo legal do setor com efeito comercial amplo surgiu em 1872, por intermédio da Associação Comercial do Rio de Janeiro. Uma regulamentação expedida naquele ano fixava, a partir de $1^{\circ}$ de julho de 1873 , a saca de café como sendo uma unidade comercial de 60 kg (BORÉM, 2008; MATIELLO, 1991).

Em 1885, usando do prestígio de serem, os Estados Unidos, o principal mercado do café brasileiro, a New York Coffee Exchange propôs uma tabela de classificação para o café beneficiado oriundo do Brasil. A tabela, que se baseava na quantidade de defeitos físicos apresentada por amostra de 450 gramas dos lotes adquiridos, integrava uma normatização que estabelecia que o produto brasileiro fosse tipificado em uma escala de nove categorias, expressas numericamente do 2 ao 10 .

A bolsa americana criava, assim, o padrão de qualidade por demérito para o café: o tipo 2, considerado de melhor qualidade, indicava um café com o mínimo de defeitos na composição de seu lote; o tipo 10 , considerado de pior qualidade, indicava cafés extremamente defeituosos. Por força de seu uso, a sistemática foi adotada no Porto de Santos em 1907, quando já influenciava o preço internacional da mercadoria (BORÉM, 2008).

Antes disso, porém, em 1904, o tipo 10 havia sido abolido da tabela de classificação. Esta categoria era equivalente à categoria do café escolha, conforme denominado pela Lei Provincial/RJ n. 33/1836. Duas décadas adiante, em 1928, o governo americano ordenou também a retirada do tipo 9 da tabela de

Quadro 1. Exemplos de descrições comerciais do café-base em algumas praças de negociação.

\begin{tabular}{|l|l|l|l|}
\hline \multicolumn{2}{|c|}{ Arábica } & \multicolumn{2}{c|}{ Robusta } \\
\hline Tipo 6, \# 17/18 & Araxá-MG & Tipo 7, até 10\% de broca & Vitória-ES \\
\hline Rio, tipo 7, \# 17/18 & Manhuaçu-MG & Tipo 7/8, brocado & Vitória-ES \\
\hline Tipo 8, bebida dura & Varginha-MG & Tipo 7/8, bica corrida & Colatina-ES \\
\hline Tipo 6/7, bebida dura & Londrina-PR & Tipo 7, até 10\% de broca & S. G. da Palha-ES \\
\hline Bica, tipo 6, dura & Barreiras-BA & 600 defeitos & Cacoal-RO \\
\hline Bica, rio, tipo 7 & Vit. da Conquista-BA & 800 defeitos & Ji-Paraná-RO \\
\hline Bica, tipo 6 & Franca-SP & & \\
\hline Tipo 6, dura/riada & Marília-SP & & \\
\hline
\end{tabular}

1) O símbolo \# indica a numeração da peneira no teste de retenção granulométrica. 2) O termo "bica" ou "bica corrida" indica granulometria desconhecida ou variada. Fonte: Elaborado com os dados da pesquisa. 
classificação. Assim como o tipo 10, o café do tipo 9 foi proibido de entrar naquele país.

O governo brasileiro oficializou o aceite da sistemática de classificação proposta por Nova York, para o café nacional, com a publicação do Decreto n. 18.796 , de 11 de junho de 1929. Por meio deste dispositivo, o Brasil regulamentou sua tabela de equivalência de defeitos para a classificação do café beneficiado, semelhante à que vigorava em Nova York e no Porto de Santos (BRASIL, 1929).

Em 14 de setembro de 1949, o governo editou o Decreto n. 27.173, responsável por novas especificações para a classificação do café. O dispositivo manteve o número de deficiências encontrado nos lotes como referência no processo de classificação. Mais preocupado em facilitar o escoamento da produção do que em criar algum tipo de padronização para o produto nacional, permitiu que não só o café pudesse ser despachado com impurezas, mas que também fosse mais barato, concorrendo em preço no mercado externo (BRASIL, 1949).

Apesar disso, o Decreto avançou em estabelecer a avaliação da qualidade do café por meio de duas classificações distintas. Além das características físicas do lote, o setor passou a atentar-se às características sensoriais do produto. Estas, por meio dos atributos da bebida, diagnosticados pela prova da xícara (CARVALHO; CHAGAS; SOUZA, 1997).

O conteúdo do Decreto 27.173/1949 refletiu-se em todos os instrumentos legais posteriores até chegar à Instrução Normativa MAPA n. 8 de 11/06/2003. Na visão de autores como Borém (2008), Carvalho, Chagas e Souza (1997), Ferrão et al. (2007), Martins (2008) e Zylbersztajn, Farina e Santos (1993), a longevidade da classificação por defeitos contribuiu para consolidar no mercado a imagem que o café brasileiro é de baixa qualidade, servindo apenas de base para misturas com cafés superiores.

\section{Procedimentos metodológicos}

A pesquisa desenvolveu-se sob abordagem qualitativa, conforme ponderações de Skinner, Tagg e Holloway (2000) e Hellebusch (2000). O método escolhido foi o estudo multicaso. Os dados foram coletados por meio da técnica da entrevista estruturada, conforme conceitos, planejamento e execução recomendados por Marconi e Lakatos (2008). Antes de serem aplicados, os instrumentos de coleta de dados utilizados foram avaliados em pré-teste.

O objeto da análise encontra-se no trecho da cadeia produtiva que envolve os processos de beneficiamento, classificação e pagamento ao produtor, na interação entre os segmentos de produção e de industrialização. As cooperativas de cafeicultores são agentes-chave neste trecho, fazendo a interação do setor produtivo, bastante numeroso e desagregado, com a indústria e com os agentes intermediários.
Segundo os dados da Conab (COMPANHIA..., 2012), as produções mais representativas de café arábica no Brasil, na safra colhida em 2011, pertenciam a Minas Gerais (68,0\%) e São Paulo (9,7\%), enquanto as produções mais representativas de café robusta pertenciam a Espírito Santo $(75,2 \%)$ e Rondônia $(12,6 \%)$. Com base nestes dados, definiu-se uma amostra não probabilística, por intencionalidade, formada por cinco grandes cooperativas localizadas nas principais regiões cafeeiras desses estados e cinco empresas torrefadoras a elas vinculadas. Na ocasião, essas regiões respondiam por $54,4 \%$ da produção nacional de café arábica (Sul-MG, Cerrado-MG e Alta Mogiana-SP) e 75,1\% da produção de café robusta (Norte-ES e RO).

Uma etapa complementar da pesquisa foi desenvolvida durante um programa de intercâmbio acadêmico, de curta duração, junto ao Institut für Betriebslehre der Agrar- und Ernährungswirtschaft, da Justus-Liebig-Universität Gießen, na cidade de Gießen, Alemanha. O país, junto com os Estados Unidos, absorve grande parte das exportações brasileiras de café. Em 2012, das 25,1 milhões de sacas exportadas pelo Brasil, $19 \%$ foram enviadas para a Alemanha, o maior mercado importador (BRASIL, 2013).

A região visitada pela pesquisa integra o maior centro de comércio do café da Europa, demarcado pelo eixo que une as cidades de Bremen e Hamburgo, ao norte do país. Nas áreas próximas ao complexo portuário local, um dos maiores do mundo em movimentação anual de contêineres, há uma grande concentração de agentes do agronegócio café: traders; representantes da indústria; torrefadoras; importadores; exportadores; corretores; e empresas de armazenamento.

Um instrumento de pesquisa de mesma natureza que o aplicado no Brasil foi elaborado para colher dados primários junto a traders alemães, importadores do café brasileiro. Três representantes deste elo foram selecionados, também por intencionalidade, levando-se em conta sua destacada presença no mercado local. Duas empresas foram visitadas na cidade de Hamburgo e uma na cidade de Bremen.

\section{Evidências empíricas}

O problema que envolve a coordenação do mercado do café beneficiado brasileiro não pode ser equacionado sem que elementos-chave, envolvidos nos processos de comercialização e de remuneração do produto, sejam considerados. Tais elementos estão presentes na concatenação lógica entre os antecedentes e as consequências do problema. Assim, a linha de análise da pesquisa adentrou, não dissociativamente, ambos os processos. 


\subsection{Orientação do sistema de pagamento}

Em determinados momentos do século passado, os preços do café brasileiro eram manipulados por mecanismos governamentais. Políticas públicas sucessivas de intervenção no setor mantiveram os preços atrelados a esses mecanismos reguladores, que operavam com precificação mínima, garantia de venda, facilitação ao crédito e controle dos estoques. A abdicação dessas políticas no final da década de 1980 permitiu ao mercado funcionar de forma livre, próximo do modelo de concorrência perfeita. Desde então, os preços no mercado interno não foram mais alvos de manipulação ou regulação governamental.

O mercado futuro do café commodity é administrado mundialmente pela Bolsa de Nova York, no caso da espécie arábica, e pela Bolsa de Londres, no caso da espécie robusta. As negociações são constantemente monitoradas pelos mercados internos dos países produtores e importadores. Corrêa e Raíces (2010) e Penick (2009) mostram que a expectativa quanto à oferta mundial do produto é o fator preponderante na flutuação dos preços nos contratos futuros do café. No Brasil, este mercado é operado pela Bolsa de São Paulo.

A causalidade entre essa flutuação de preços e a cotação do produto no mercado brasileiro é, vez ou outra, verificada empiricamente. Análises recentes, por exemplo, de Ferreira et al. (2011), Mineo (2010), Nishijima, Saes e Postali (2012), Nogueira e Aguiar (2011) e Santos et al. (2012), mostram que, diferentemente de outras épocas em que a demanda mundial de café era suprida em mais de $50 \%$ pelo Brasil, hoje a oferta internacional é diversificada e está submetida, em primeira instância, à bienalidade inerente à cultura. Os derivativos (contratos futuros) da cultura negociados nas Bolsas de Nova York, Londres, ou mesmo de São Paulo servem prioritariamente a investidores com propósitos financeiros que percebem a commodity não como mercadoria física, mas como instrumento de negociação.

No mercado interno, os preços sofrem variações em função da região em que o produto é negociado. Mas, segundo Nogueira e Aguiar (2011), o mercado comporta-se de modo integrado. Apesar de a produção ser desdobrada em duas espécies e a cotação ser fixada para diferentes padrões classificatórios, a movimentação dos preços tende a ser correlacionada. Os autores afirmam que a reação dos preços nas regiões produtoras a choques de oferta e demanda é congênere.

Os depoimentos colhidos nos treze agentes desta pesquisa (cooperativas, torrefadoras e traders) mostram que a remuneração do setor produtivo baseia-se na cotação diária de um produto considerado base em uma determinada praça. Essas praças, normalmente cidades cuja economia é fortemente dependente deste agronegócio, utilizam mais de um café como base. A suposta qualidade do produto negociado é comparada à qualidade do café-base considerado, orientando a precificação. Teoricamente, o preço do produto negociado pode situar-se acima da cotação do café-base, desde que sua qualidade percebida seja reconhecida como superior à qualidade deste.

A formação da qualidade percebida deve-se, em grande parte, à descrição do produto via classificação oficial, uma vez que o café-base é categorizado e descrito por este instrumento e a mensuração dos atributos intrínsecos, no momento da negociação, geraria custos proibitivos. A classificação, como mencionado, prioriza o aspecto da bebida e, fundamentalmente, as características físicas do produto. Desse modo, a pesquisa verificou que, na ausência de indicadores mais representativos a respeito de sua qualidade, os defeitos do café ganham importância significativa em sua precificação. A avaliação da qualidade do produto negociado é caracterizada pela refutação da não qualidade. Ao posicionar o indicador de defeitos na base da precificação, o sistema classificatório cria o estigma que o café bom, de fato, é o café "menos ruim".

Outra constatação da pesquisa é que a classificação oficial não padroniza corretamente os cafés em circulação no país. Nem sempre a diferença de tipo verificada entre dois lotes, que é suficiente para depreciar o lote de tipo mais alto, está correlacionada a cafés com atributos de bebida distintos. De forma análoga, não necessariamente o café mais defeituoso possui bebida pior. Boa parte dos defeitos físicos, na verdade, é eliminada na etapa de rebeneficiamento, que as cooperativas, traders e exportadores realizam após receberem lotes diretamente de cafeicultores (o rebeneficiamento é um processo automatizado que consiste, basicamente, de uma nova catação, para eliminação dos defeitos físicos, e uma nova peneiração, para homogeneização granulométrica dos lotes).

A ineficiência do sistema de classificação em distinguir os lotes de melhor qualidade significa, na prática, que alguns cafés são remunerados de forma inadequada. Portanto, se o pagamento ao produtor for orientado apenas pela descrição comercial do lote, dificilmente o produto será remunerado por sua qualidade intrínseca. Da forma como o mercado doméstico está orientado, o preço pago ao produtor pela unidade (saca de $60 \mathrm{~kg}$ ) do produto café beneficiado, em um determinado tempo $t$, é definido segundo a Equação 1.

$$
P=f\left(C, Q_{p}, Z, E\right)
$$

Em que: $P$ : preço pago ao produtor;

$C$ : cotação do café-base considerado;

$Q_{p}$ : qualidade percebida pelo comprador;

$Z$ : variáveis exógenas;

$E$ : erro aleatório. 
A variável $C$ aparenta estar mais intimamente relacionada à oferta e ao consumo interno do produto, mas não se descarta a possibilidade de haver certa variabilidade em função das flutuações de preços no mercado externo e no mercado futuro. $\mathrm{O}$ efeito em $P$ desta variabilidade constitui parte das interveniências esperadas de $Z$. A variável $Q_{p}$ parece estar fortemente relacionada ao aspecto geral, aos defeitos da amostra e à expectativa do comprador quanto à qualidade da bebida, mas também à distribuição granulométrica do lote. O modelo matemático é útil, pois sintetiza as evidências empíricas observadas, mas o teste de influência de suas variáveis requer estudo específico, que ultrapassa o escopo desta pesquisa.

\subsection{Macrossegmento de produção: as cooperativas de cafeicultores}

As cinco cooperativas visitadas pela pesquisa possuem sede e atuação nas principais regiões cafeeiras do país. A Tabela 1 apresenta alguns dados sobre o quadro administrativo e o desempenho de mercado dessas empresas, referentes ao ano de 2011. Sua representatividade no mercado nacional pode ser percebida pelo volume de movimentação: as cooperativas A, B e C absorveram, juntas, $16 \%$ do volume produzido de café arábica no país naquele ano, enquanto as cooperativas D e E absorveram $10,2 \%$ do volume produzido de café robusta. A menor expressividade da cooperativa E, comparada a das outras quatro, justifica-se por ela ser uma cooperativa formada basicamente por produtores de agricultura familiar.

Das cinco cooperativas, quatro possuem implantado algum tipo de sistema próprio de classificação, de funcionamento interno, como alternativa ao sistema oficial. Tanto para categorizar melhor seu produto, como para remunerar seus cooperados. O que atesta que a necessidade de intervenção no mecanismo coordenador desse mercado é patente.

Dos quatro sistemas alternativos de classificação vistos, três constituem um mecanismo praticamente independente do sistema oficial (Coop-A, Coop-B e Coop-C). O quarto sistema (Coop-D) ainda é bastante atrelado ao sistema oficial, tendo apenas modificado alguns de seus procedimentos. Segundo os entrevistados, a classificação interna, comparada à oficial, permite negociações no mercado com maior eficácia, com relação às características do produto que se quer adquirir ou vender. A quinta cooperativa (Coop-E), apesar de ainda não ter se desprendido do sistema oficial, percebe tal necessidade em função dos mesmos objetivos.

A pesquisa procurou captar a percepção do entrevistado quanto à importância do sistema oficial nas negociações, independentemente da cooperativa possuir ou não alternativas ao sistema. De uma lista prévia com dez afirmativas, sete foram selecionadas após o pré-teste do instrumento de pesquisa e apresentadas aos entrevistados, que deveriam assinalar sua aceitação ou contestação com relação a cada uma delas, baseando-se em uma escala do tipo Likert de 1 (um) a 5 (cinco), na qual 1 significava discordo totalmente e 5 significava concordo totalmente. As respostas foram sumarizadas na Tabela 2.

Com poucos respondentes, optou-se por analisar as respostas individualmente. Contudo, sem desprezar a tendência central. Os resultados mostram que, nas solicitações de compra que as cooperativas recebem de seus clientes, nem sempre os produtos são discriminados conforme sua descrição comercial dada pela classificação oficial. Os clientes optam

Tabela 1. Caracterização das cooperativas da pesquisa, com referência no ano civil de 2011.

\begin{tabular}{|c|c|c|c|c|c|c|}
\hline \multicolumn{2}{|c|}{ Indicadores } & Coop-A & Coop-B & Coop-C & Coop-D & Coop-E \\
\hline \multicolumn{2}{|c|}{ Sede (Unidade da Federação) } & MG & MG & SP & ES & RO \\
\hline \multicolumn{2}{|c|}{ Ano de fundação } & 1957 & 1995 & 1985 & 1963 & 1989 \\
\hline \multicolumn{2}{|c|}{ Número de funcionários } & 1.917 & 158 & 201 & 198 & 33 \\
\hline \multicolumn{2}{|c|}{ Número de cooperados } & 11.875 & 378 & 2.000 & 4.103 & 390 \\
\hline \multicolumn{2}{|c|}{ Perfil dos cooperados (porte) } & peq & méd a grd & méd & peq & agric. familiar \\
\hline \multicolumn{2}{|c|}{ Volume recebido (mil sacas) } & 4.166 & 1.134 & 900 & 908 & 18 \\
\hline \multicolumn{2}{|c|}{$\%$ da produção regional } & $32 \%$ & $20 \%$ & $54 \%$ & $15 \%$ & $1 \%$ \\
\hline \multirow{2}{*}{$\begin{array}{l}\text { \% da produção } \\
\text { nacional de: }\end{array}$} & Arábica & $11 \%$ & $3 \%$ & $2 \%$ & - & - \\
\hline & Robusta & - & - & - & $10 \%$ & $0,2 \%$ \\
\hline \multicolumn{2}{|c|}{ Cap. armaz. própr. (mil sacas) } & 3.500 & 700 & 1.000 & 800 & 100 \\
\hline \multirow{2}{*}{$\begin{array}{l}\text { Vendas } \\
\text { (mil sacas) }\end{array}$} & Merc. interno & 2.662 & 433 & 400 & 890 & 0,4 \\
\hline & Merc. externo & 2.466 & 195 & 20 & - & 1 \\
\hline \multicolumn{2}{|c|}{ Vendas líquidas (US\$ milhões) } & $1.591,2$ & 165,5 & 208,1 & 142,5 & 0,2 \\
\hline \multicolumn{2}{|c|}{ Ativo total (US\$ milhões) } & $1.188,5$ & 58,2 & 151,5 & 47,0 & não inf. \\
\hline
\end{tabular}

Fonte: Elaborada com os dados da pesquisa. 
Tabela 2. Percepção dos entrevistados sobre a importância do sistema oficial de classificação do café.

\begin{tabular}{|c|c|c|c|c|c|}
\hline \multirow[b]{2}{*}{ Afirmativas } & \multicolumn{5}{|c|}{ Número de respostas } \\
\hline & 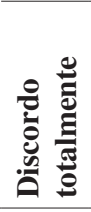 & 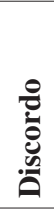 & 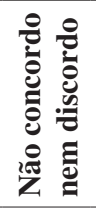 & $\stackrel{0}{\stackrel{0}{0}}$ & 율 \\
\hline $\begin{array}{l}\text { Quando a cooperativa vende café beneficiado, as especificações de compra } \\
\text { recebidas são baseadas na classificação do produto segundo o sistema oficial. }\end{array}$ & - & 2 & - & 3 & - \\
\hline $\begin{array}{l}\text { Quando a cooperativa compra café beneficiado, já classificado pelo sistema } \\
\text { oficial, há confiança na classificação apresentada, independentemente do } \\
\text { fornecedor do produto. }\end{array}$ & 4 & 1 & - & - & - \\
\hline $\begin{array}{l}\text { O café beneficiado classificado segundo o sistema oficial brasileiro tem } \\
\text { seus atributos de qualidade suficientemente evidenciados para o comprador, } \\
\text { permitindo que ele adquira o produto exatamente no padrão de qualidade que } \\
\text { deseja. }\end{array}$ & 2 & 2 & - & 1 & - \\
\hline $\begin{array}{l}\text { A classificação do café beneficiado, segundo o sistema oficial brasileiro, é um } \\
\text { processo que padroniza, pela qualidade, todo o produto em circulação no país. }\end{array}$ & 1 & 3 & 1 & - & - \\
\hline $\begin{array}{l}\text { É fundamental, para o segmento produtivo, que haja um sistema oficial de } \\
\text { classificação do café beneficiado no país. }\end{array}$ & - & - & - & 1 & 4 \\
\hline $\begin{array}{l}\text { O cafeicultor brasileiro que tem seu café beneficiado devidamente classificado } \\
\text { pelo sistema oficial consegue auferir uma remuneração justa por seu produto. }\end{array}$ & 3 & 1 & 1 & - & - \\
\hline $\begin{array}{l}\text { O segmento produtivo da cadeia do café, de um modo geral, NÃO tem } \\
\text { reclamações a respeito do sistema oficial de classificação do produto. }\end{array}$ & 3 & 2 & - & - & - \\
\hline
\end{tabular}

Fonte: Elaborada com os dados da pesquisa.

por utilizar a descrição do produto conforme a sistemática da própria cooperativa. Em duas delas, notou-se que a colocação de pedidos é realizada quase que exclusivamente mediante a terminologia da classificação interna.

Segundo os entrevistados, geralmente os clientes especificam poucas características do produto, priorizando aquelas que essencialmente necessitam saber, como a quantidade de grãos pretos, verdes e ardidos nas amostras de avaliação (denominado defeito PVA), a classificação por peneiras, a bebida e a origem, principalmente. Isso no caso de clientes de maior porte ou importadores. Na região da Coop-D, a quantidade de grãos brocados também é critério de compra. Na região da Coop-E, os compradores indagam sobre a quantidade de defeitos no geral, sem distinção.

$\mathrm{Na}$ negociação inversa, geralmente os lotes adquiridos pela cooperativa fora do ambiente cooperativista são ofertados com a descrição comercial oficial (ou parte dela). Mas raramente a classificação é aceita. Os entrevistados demonstraram que há forte desconfiança com relação à exatidão dessas informações, explicando que preferem reclassificar o café com seu sistema interno. Principalmente para verificarem a granulometria, a bebida e um indicador denominado percentual de catação, não presente na classificação oficial. As poucas exceções ocorrem no caso de transações de lotes entre cooperativas específicas, em virtude da reputação mútua construída.

Houve tendência dos entrevistados em refutar as duas afirmativas a favor da eficiência do sistema oficial: uma com relação ao sistema conseguir evidenciar ao comprador os atributos de qualidade dos lotes e a outra com relação à padronização dos lotes em circulação no país. Eles justificaram a refutação de ambas contestando o modo como o sistema oficial está categorizado e o processo de amostragem dos lotes.

Nas cooperativas com sistema próprio de classificação, os entrevistados foram instruídos a qualificar o desempenho de seu sistema interno, comparando-o com o sistema oficial, mediante 16 características. Para cada característica, foi concedida uma nota de 1 (um) a 5 (cinco), em escala Likert, na qual 1 significava péssimo e 5 significava excelente. As respostas dos quatro respondentes foram somadas, considerando seu valor numérico dado. $\mathrm{O}$ resultado final de cada característica foi comparado entre um sistema e outro na nova escala com os valores somados: 4 (quatro) a 20 (vinte), em que 4 é o valor mínimo porque representa a soma de quatro notas 1 (um), e 20 é o valor máximo porque representa a soma de quatro notas 5 (cinco). Os resultados foram transportados para a Figura 1.

Segundo Hora, Monteiro e Arica (2010), a aferição da confiabilidade deste tipo de constructo por meio 


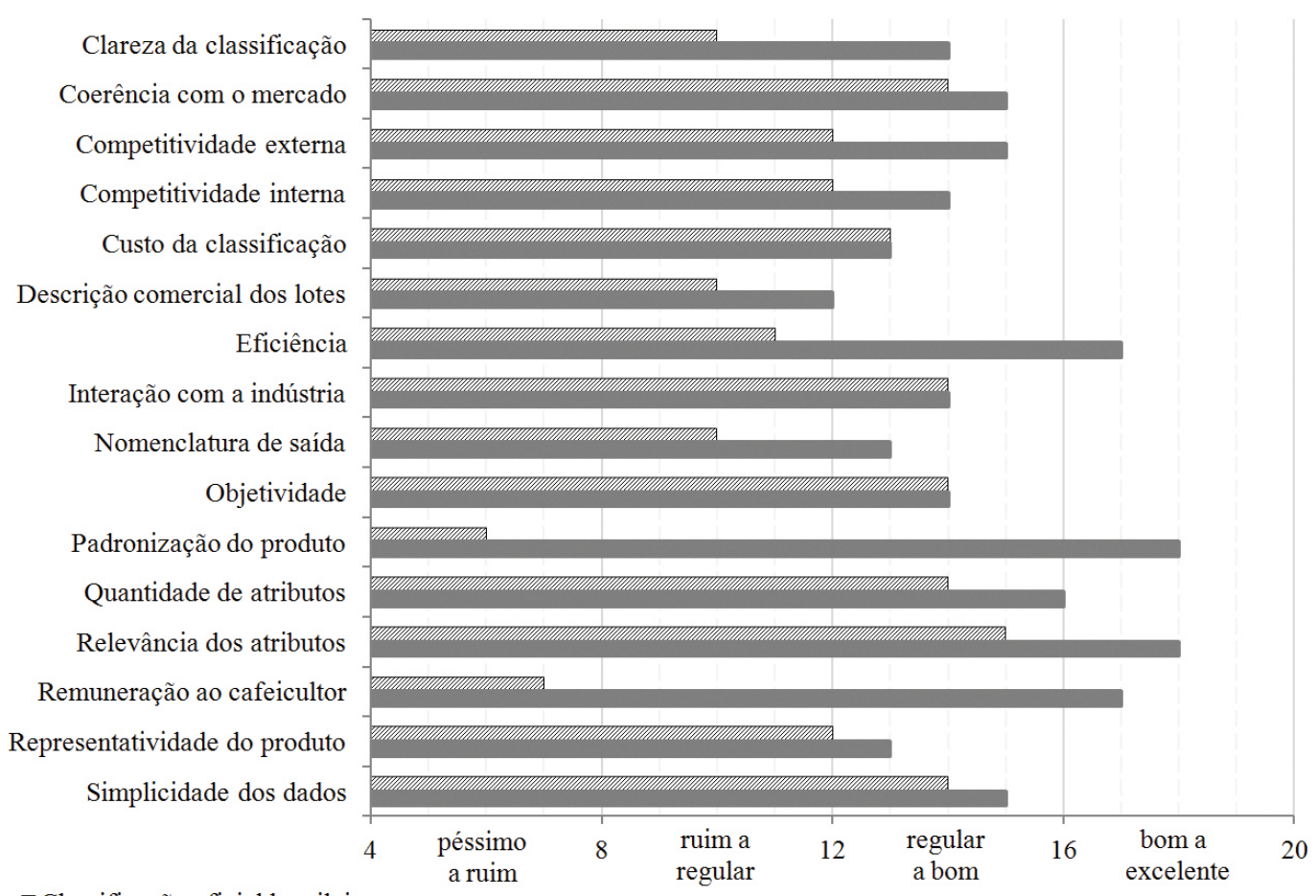

ש Classificação oficial brasileira

Sistema interno das cooperativas

Figura 1. Avaliação comparativa do desempenho dos sistemas internos das cooperativas com o sistema oficial.

de coeficientes internos, como o alfa de Cronbach ou algum outro semelhante, pode ser dispensada pelo fato do questionário ter sido respondido por especialistas no assunto em pauta. Neste caso, a própria avaliação dos respondentes é mais recomendada do que o uso desses coeficientes.

As características que mais se destacaram, proclamando o melhor desempenho dos sistemas internos das cooperativas, foram: clareza na classificação; eficiência do processo; remuneração ao produtor; e padronização do produto. Pelo menos três características foram avaliadas como de desempenho semelhante tanto na classificação interna como na oficial: custo da classificação, interação com a indústria e objetividade. Nenhuma delas teve o desempenho considerado melhor quando empregado o sistema oficial.

A contribuição maior deste trecho das entrevistas foi a constatação de que esses sistemas internos são utilizados para balizar as negociações, estão postos como alternativa às carências do sistema oficial e possuem relação direta com o pagamento ao produtor. Ao que parece, se isoladas as variáveis associadas à ocasião e às condições de mercado, que também afetam o preço final numa negociação, a precificação a partir dos critérios não oficiais de classificação parece ser entendida como mais coerente e justa para o setor produtivo. Para os objetivos desta pesquisa, importa perceber que os sistemas das cooperativas estão efetivamente orientando a formação de preços ao produtor e estão conseguindo evidenciar melhor os atributos de qualidade que caracterizam os lotes classificados.

\subsection{Macrossegmento de industrialização: as torrefadoras}

As empresas de torrefação são os principais agentes representantes deste macrossegmento da cadeia produtiva. Deste ponto em diante, o café beneficiado deixa de ser uma commodity e o processo de transformação gera os preparados para a constituição da bebida pelo consumidor: café torrado e moído, café torrado em grãos e café solúvel, principalmente, segundo denominações empregadas pela Associação Brasileira da Indústria do Café (ABIC).

As torrefadoras visitadas pela pesquisa, caracterizadas na Tabela 3, produzem basicamente o café torrado, em suas formas moído ou em grãos. Duas delas comercializam também o café solúvel, mas não possuem marca própria nesse segmento.

As torrefadoras A, C e E são empresas administrativamente vinculadas às cooperativas $\mathrm{A}$, $\mathrm{C}$ e E. As três trabalham basicamente com os cafés de suas cooperativas, mas adquirem cafés de não cooperados para a formação de misturas específicas, 
Tabela 3. Caracterização das torrefadoras da pesquisa.

\begin{tabular}{lccccc}
\hline \multicolumn{1}{c}{ Indicadores } & A & B & C & D & E \\
\hline $\begin{array}{l}\text { Situação da torrefadora } \\
\text { com relação à cooperativa }\end{array}$ & própria & $\begin{array}{l}\text { prestadora } \\
\text { de serviço }\end{array}$ & própria & cliente & própria \\
Marcas comercializadas: & 05 & 01 & 03 & - & 02 \\
Próprias da cooperativa & 15 & - & 04 & - & - \\
Vinculadas à cooperativa & - & 03 & - & 06 & - \\
Não próprias e sem vínculo & 20 & 04 & 07 & 06 & 02 \\
Total & 220 & 120 & 50 & 200 & 20 \\
Vendas mensais (ton) - 2011 & & & & & \\
\hline
\end{tabular}

Fonte: Elaborada com os dados da pesquisa.

conhecidas como blends. A torrefadora B, na ocasião, era a empresa única contratada pela Coop-B para a industrialização de sua marca própria. Mas os cafés da Coop-B seguem também para outras torrefadoras. A torrefadora $\mathrm{D}$, apesar de não possuir nenhum vínculo, nem mesmo contratual, com a Coop-D, era uma de suas principais clientes, considerando suas vendas à indústria. A empresa possui produção própria de matéria-prima, mas insuficiente para suprir sua demanda.

Na média, aproximadamente $75 \%$ do volume de café adquirido por essas torrefadoras, não provenientes das respectivas cooperativas, advêm de traders ou diretamente do produtor. No caso das torrefadoras $\mathrm{A}, \mathrm{C}$ e E, quando suas cooperativas adquirem lotes especificamente destinados à industrialização, os critérios de compra são definidos pela torrefadora. Esses critérios são relativamente comuns a todas as cinco, sendo parametrizados pela origem, índice de catação (ou número de defeitos, na ausência deste índice), natureza dos defeitos, granulometria e resultado do teste da bebida, principalmente para acidez, corpo e amargor.

Geralmente não há contratos formais com os fornecedores. A abundância da matéria-prima no mercado interno, segundo os entrevistados, torna essa formalidade desnecessária. Além disso, a fixação de contratos aumentaria o risco futuro da empresa em suas aquisições, uma vez que os preços são flutuantes. Ambos os fatores, elevada oferta e preços flutuantes, concedem à indústria um considerável poder de barganha nas negociações.

Os entrevistados do setor industrial, em concordância com os das cooperativas, não acreditam que a classificação oficial vigente seja eficaz quanto à padronização dos cafés do país. Segundo eles, não é incomum o recebimento de lotes de mesma descrição comercial e características distintas. O sistema é propenso a falhas de manipulação, mas também é incapaz de retratar os cafés com precisão. A pesquisa constatou que, devido a esta imprecisão do sistema, e tal qual o problema visto sob a óptica dos produtores, se as torrefadoras basearem suas decisões de compra apenas no preço e na descrição comercial do produto, dificilmente conseguirão adquirir lotes de matéria-prima com a qualidade requerida.

A compensação, neste caso, é que a tecnologia lhes permite manipular determinados atributos dessa qualidade durante o processo de torra. Por meio de misturas de diferentes cafés (blends), as torrefadoras conseguem conferir ao produto final algumas qualificações desejáveis. Entretanto, essa manipulação limita-se às características dos cafés disponíveis e não significa, necessariamente, melhoria de qualidade. A formação de alguns blends chega a envolver seis a oito lotes distintos, o que torna o processo dispendioso.

Os atributos de qualidade do café beneficiado que mais interessam à indústria são os que mais podem comprometer as propriedades sensoriais de aroma, sabor e corpo da bebida. A composição do sabor é complexa, sendo definida em conjunto com atributos específicos que avaliam a acidez, o amargor, o teor de açúcar, o gosto residual, o equilíbrio e a adstringência. Como esses atributos não podem ser medidos a baixo custo, sua contratação exige a coordenação de um sistema de classificação que forneça os indicadores necessários. Tarefa que os entrevistados entendem que o sistema oficial não realiza em plenitude.

\subsection{Agentes intermediários: os traders importadores}

Os traders são agentes que operam na intermediação entre os macrossegmentos de produção e de industrialização da cadeia produtiva, podendo atuar na compra e venda do produto em seu mercado doméstico, na importação e exportação e no rebeneficiamento dos lotes para agregação de valor.

Alguns dados referentes às três empresas visitadas, na Alemanha, encontram-se na Tabela 4. Essas empresas foram selecionadas a partir de uma relação prévia elaborada somente com traders locais que mantinham relacionamento com fornecedores de cafés no Brasil. Essa relação prévia, incompleta em relação ao universo de possibilidades, contemplava seis empresas cuja receptividade à pesquisa fora anteriormente verificada. 
Tabela 4. Caracterização das empresas traders entrevistadas na Alemanha.

\begin{tabular}{|c|c|c|c|c|}
\hline \multicolumn{2}{|l|}{ Indicadores } & Trader A & Trader B & Trader C \\
\hline \multicolumn{2}{|l|}{ Cidade-sede } & Hamburgo & Hamburgo & Bremen \\
\hline \multicolumn{2}{|l|}{ Ano de fundação } & 1992 & 1978 & 1981 \\
\hline \multirow[t]{2}{*}{ Número de países fornecedores* cadastrados } & Arábica & 16 & 22 & 18 \\
\hline & Robusta & 4 & 5 & 4 \\
\hline \multicolumn{2}{|l|}{ Volume total importado, 2011 (mil sacas) } & 90 & 510 & 250 \\
\hline \multicolumn{2}{|l|}{ Volume importado do Brasil (\%) } & $29 \%$ & $22 \%$ & $33 \%$ \\
\hline \multicolumn{2}{|l|}{ Capacidade de armazenamento (mil sacas) } & 120 & 550 & 400 \\
\hline \multicolumn{2}{|l|}{ Capacidade de rebeneficiamento (mil sacas/dia) } & 6 & 18 & 15 \\
\hline
\end{tabular}

*Alguns países fornecem ambas as espécies, $C$. arabica e $C$. canephora. Fonte: Elaborada com os dados da pesquisa.

Durante as entrevistas, foi especialmente observada a forma como as empresas descreviam seus pedidos de compra. $\mathrm{O}$ objetivo era tentar perceber quais atributos de qualidade eram ressaltados na descrição e como essas empresas distinguiam os cafés que queriam adquirir.

Notou-se que a descrição comercial gerada pela classificação brasileira leva ao exterior dois elementos às vezes únicos: o tipo e a granulometria do lote. A classificação quanto à bebida, quando não acompanha a descrição, costuma estar descrita à parte ou é subentendida pelo comprador, no caso de descrições que se referem a cafés conhecidos.

Alguns elementos não são contemplados pelo sistema oficial brasileiro, mas aparecem constantemente nas descrições dos cafés das empresas importadoras, como a região de origem do produto, o processo de beneficiamento utilizado pelo produtor (basicamente identificado se via seca ou via úmida) e, por vezes, a fazenda de cultivo. O termo Santos, menção ao principal porto de embarque da cultura no mundo durante o auge do domínio produtivo do Brasil, no século XIX, ainda é empregado como referência a cafés brasileiros no exterior, seja ele oriundo de qualquer região produtora. As indicações de origem e do processo de beneficiamento costumam ser suficientes para os importadores quanto às características esperadas da bebida.

Os importadores alemães avaliam criteriosamente a qualidade esperada da bebida, uma vez que as torrefadoras produzem cafés específicos em atributos de aroma e sabor. Esses atributos podem ser comprometidos pela falta de homogeneidade dos grãos no processo de torra. Por isso, a indicação do padrão granulométrico dos lotes é fundamental neste mercado. Segundo os entrevistados, praticamente não há requisições de compra sem esta especificação.

Normalmente, a mesma terminologia empregada pelos fornecedores para especificar seus produtos é utilizada nos processos de compra dessas firmas. $\mathrm{Na}$ venda, os traders repetem a descrição original para seus clientes. No caso dos fornecedores brasileiros, essa terminologia pode ser a oficial ou a adotada pelas cooperativas ou exportadores. Mas, segundo os entrevistados, na maioria das transações, os cafés são negociados com descrições comerciais não oficiais. Não foi possível, contudo, precisar essa informação em percentual de negociações totais.

Eles avaliam as descrições dos cafés brasileiros, via sistema oficial, como deficientes, quando comparadas com a maior parte das descrições de cafés de outros países fornecedores. Principalmente com relação a características como representatividade, credibilidade e completude. Na opinião desses agentes, a descrição brasileira não fornece segurança suficiente ao importador para adquirir o produto com as características devidas.

As descrições não oficiais, entretanto, geradas a partir de sistemas classificatórios como os das cooperativas da pesquisa, parecem estar mais condizentes com os requisitos do mercado e conceder mais credibilidade aos traders. Notadamente as que acrescentam a indicação da origem, do processo de beneficiamento e que especificam o percentual de defeitos capitais específicos.

No contexto geral, os traders percebem o café brasileiro como de qualidade mediana. Os bons ou excelentes são exceções, podendo ser identificados na compra apenas por meio de descrições comerciais não oficiais. Os cafés colombianos e centro-americanos são percebidos como os melhores do mundo. Quanto aos fornecedores do sudeste asiático, o café do Vietnã é considerado muito defeituoso, ao passo que os cafés provenientes das ilhas vulcânicas da Indonésia são vistos como de qualidade destacada.

A percepção desta qualidade, não apenas pelos traders da pesquisa, mas pelo mercado europeu de um modo geral, pode estar refletida na prática de preços pagos aos fornecedores e nos preços de revenda. A pesquisa observou, nas três empresas, pouco mais de duas centenas de descrições diferentes de cafés cadastradas. Tomando-se apenas os que possuíam estoque ou estavam em negociação naquele momento, os cafés foram agrupados segundo a espécie e segundo serem ou não certificados por algum mecanismo internacional. $\mathrm{O}$ desempenho em preço dos cafés brasileiros foi comparado ao dos cafés dos demais países fornecedores. Os extremos desse desempenho são mostrados na Tabela 5 . 
Tabela 5. Precificações extremas na revenda dos cafés dos traders da pesquisa (referência em 29/5/2012).

\begin{tabular}{|c|c|c|c|}
\hline \multicolumn{2}{|l|}{ ARÁBICA } & \multicolumn{2}{|l|}{ ROBUSTA } \\
\hline Descrição & US\$/saca & Descrição & US\$/saca \\
\hline \multicolumn{4}{|c|}{ Pior precificação, entre os cafés brasileiros: } \\
\hline Santos $4 / 5$ scr $12+$ crop $10 / 11$ & 166,55 & Brazil robusta NY 5 & 127,60 \\
\hline \multicolumn{4}{|c|}{ Pior precificação geral (todos os países fornecedores): } \\
\hline Santos $4 / 5$ scr $12+$ crop $10 / 11$ & 166,55 & Uganda undergrade $75 \%>$ scr 12 & 119,82 \\
\hline \multicolumn{4}{|c|}{ Melhor precificação, entre os cafés brasileiros (lotes sem certificação): } \\
\hline Brazil fully washed scr $14+$ & 234,00 & Conilon capixaba wet 14 & 145,60 \\
\hline \multicolumn{4}{|c|}{ Melhor precificação geral (lotes sem certificação): } \\
\hline Sumatra Mandheling DP grd 1 & 334,50 & Vietnam wet polished grd $1 \# 18$ & 161,82 \\
\hline \multicolumn{4}{|c|}{ Melhor precificação, entre os cafés brasileiros (lotes certificados): } \\
\hline Minas Gerais 2 scr 17/18 UTZ & 248,00 & - & - \\
\hline \multicolumn{4}{|c|}{ Melhor precificação geral (lotes certificados): } \\
\hline Sumatra Mandheling DP grd 1 FLO & 400,70 & Guatemala washed $10 / 11$ special & 242,82 \\
\hline
\end{tabular}

Fonte: Elaborada com os dados da pesquisa.

$\mathrm{Na}$ ocasião, os arábicas brasileiros não demonstravam bom desempenho em preço com relação a seus concorrentes mais fortes, os cafés colombianos e centro-americanos, mas estavam abaixo também dos cafés da Indonésia, Etiópia, Quênia, Uganda e Tanzânia. Os cafés nacionais com melhor desempenho eram os oriundos das regiões do Cerrado, dos Estados da Bahia e de Minas Gerais. O melhor deles, o Minas Gerais 2 scr 17/18 com certificação dada pela holandesa UTZ Kapeh Foundation, estava $21 \%$ mais barato que o café colombiano com pior desempenho (Colombia Excelso EP, US\$312,00/saca) e apenas $6 \%$ mais caro que o melhor café brasileiro não certificado (Brazil fully washed scr 14+).

Já o desempenho do conilon brasileiro diante dos robustas internacionais parece ser melhor. Inclusive com relação à maioria dos cafés do Vietnã, o maior produtor mundial da espécie. O melhor robusta sem certificação, no entanto (Vietnam wet polished grd 1 \#18), era proveniente desse país asiático e estava $11 \%$ mais caro que o conilon brasileiro com melhor desempenho (Conilon capixaba wet 14). Entre os dessa espécie não havia nenhum café brasileiro com certificação nas empresas visitadas.

É preciso levar em conta que o preço alcançado pelos diferentes cafés neste mercado, e neste ponto da cadeia produtiva, depende de uma série de fatores e que muitos deles transpõem o escopo desta pesquisa. Chama a atenção, porém, a contribuição negativa que a classificação oficial brasileira, na forma como padroniza e descreve os cafés da produção nacional, tem gerado no desempenho do produto nos mercados internacionais.

Diferentemente dos demais países produtores, o Brasil produz cafés com qualidades distintas. Mas a correta remuneração do produto nacional depende de esta variabilidade produtiva estar suficientemente visível aos compradores no ato da negociação. Os cafés brasileiros precisam ser percebidos e avaliados a partir da qualidade de seus atributos, e não mais a partir de seus defeitos físicos.

\section{Conclusões}

Embora o café seja uma das principais commodities agrícolas do país, seu mercado é coordenado por um mecanismo arcaico, falho e ineficiente. O sistema oficial brasileiro responsável pela classificação e padronização dos lotes conserva a mesma essência desde os primórdios do estabelecimento do marco regulatório, no final do século XIX. Sua ênfase nos defeitos físicos do produto é contraproducente no atual ambiente mercadológico globalizado, no qual a competitividade das cadeias produtivas baseia-se na excelência.

Erroneamente, o mecanismo desprestigia o produto distinto em qualidade e afeta negativamente o sistema de pagamento, o que inviabiliza, por exemplo, o retorno de investimentos em diferenciação porventura realizados no processo de produção. O fenômeno notado assemelha-se à observação de Akerlof (1970) para mercados ineficientes, caracterizados pela existência de assimetria de informação entre as partes negociantes. $\mathrm{O}$ autor demonstra que, se um produto costuma ser ofertado com qualidades diferentes e os detalhes dessa informação não são disponibilizados ao comprador, há uma tendência de ineficiência porque as transações acontecem baseadas em informações imperfeitas.

As cooperativas de cafeicultores têm buscado contornar o problema adotando métodos alternativos de classificação, baseados em quesitos desenvolvidos internamente. $\mathrm{O}$ artifício é um importante indicativo da insatisfação do setor produtivo com o mecanismo oficial. Esses agentes têm conseguido, dessa forma, orientar o pagamento do produto de modo mais 
coerente e justo. Coerente, no sentido de os lotes de mesma categoria possuírem, de fato, atributos intersemelhantes e relevantes para o mercado, e justo, no sentido de o produtor ser remunerado corretamente por seu produto.

A estratégia revela-se benéfica não apenas aos cooperados, como também possibilita a melhor colocação do produto no mercado na revenda. Os cafés dessas empresas negociados com o setor industrial ou com agentes intermediários, inclusive no exterior, são descritos preferencialmente a partir de seus sistemas internos de classificação. Essa intervenção na coordenação do mercado tem conseguido desfavorecer a concorrência em preço e permitido a ascensão de cafés diferenciados pela qualidade. O que evidencia a necessidade de reformulação do mecanismo oficial e, por conseguinte, de reestruturação na governança da cadeia.

\section{Agradecimentos}

Os autores agradecem à Coordenação de Aperfeiçoamento de Pessoal de Nível Superior (CAPES) e ao Deutscher Akademischer Austauschdienst (DAAD) o apoio financeiro concedido, e ao Prof. Dr. Rainer Kühl, do Institut für Betriebslehre der Agrar- und Ernährungswirtschaft, da Universität Gießen (Alemanha), o apoio acadêmico.

\section{Referências}

AKERLOF, G. A. The market for "lemons": qualitative uncertainty and the market mechanism. Quarterly Journal of Economics, v. 84, n. 3, p. 488-500, 1970. http://dx.doi.org/10.2307/1879431

AZEVEDO, P. F. de. Nova Economia Institucional: referencial geral e aplicações para a agricultura. Agricultura em São Paulo, v. 47, n. 1, p. 33-52, 2000.

BARZEL, Y. Measurement costs and the organization of markets. The Journal of Law and Economics, v. 25, n. 1, p. 27-48, 1982. http://dx.doi.org/10.1086/467005

BARZEL, Y. Productivity change, public goods, and transaction costs: essays at the boundaries of microeconomics. Aldershot: E. Elgar, 1995. 473 p. (Economists of the Twentieth Century).

BARZEL, Y. Economic analysis of property rights. 2. ed. Nova York: Cambridge University Press, 1997. 161 p. http://dx.doi.org/10.1017/CBO9780511609398

BARZEL, Y. Organizational forms and measurement costs. Journal of Institutional and Theoretical Economics, v. 161, n. 3, p. 357-373, 2005. http:// dx.doi.org/10.1628/093245605774259291

BORÉM, F. M. (Ed.). Pós-colheita do café. Lavras: EdUFLA, 2008. $631 \mathrm{p}$.

BRASIL. Atos do Poder Executivo. Decreto no 18.796, de 11 de junho de 1929. Dá novo regulamento à Bolsa de Mercadorias do Districto Federal. Diário Oficial da União, Poder Executivo, Rio de Janeiro, RJ, 15 jun. 1929. Seção 1, p. 13653-13656.
BRASIL. Atos do Poder Executivo. Decreto no 27.173, de 14 de setembro de 1949. Aprova as especificações e tabelas para a classificação e fiscalização do café, visando sua padronização. Diário Oficial da União, Poder Executivo, Rio de Janeiro, RJ, 16 set. 1949. Seção 1, p. 13364.

BRASIL. Ministério da Agricultura, Pecuária e Abastecimento. Instrução Normativa $n^{\circ} 8$, de 11 de junho de 2003. Diário Oficial da União, Poder Executivo, Brasília, DF, 13 jun. 2003. Seção 1, p. 4-6.

BRASIL. Ministério do Desenvolvimento, Indústria e Comércio Exterior. Secretaria de Comércio Exterior - Secex. AliceWeb 2: Sistema de Análise das Informações de Comércio Exterior. Brasília, 2013. Disponível em: <http://aliceweb2.mdic.gov.br>. Acesso em: 23 jan. 2013.

CARVALHO, V. D.; CHAGAS, S. J. R.; SOUZA, S. M. C. de. Fatores que afetam a qualidade do café. Informe Agropecuário, v. 18, n. 187, p. 5-20, 1997.

C O M P A H A N A C I O N L D D E ABASTECIMENTO - CONAB. Acompanhamento da safra brasileira: café. Safra 2012, primeira estimativa, janeiro/2012. Brasília: Conab, 2012. 18 p. Disponível em: <http://www.conab.gov.br>. Acesso em: 18 jul. 2012.

CORRÊA, A. L.; RAÍCES, C. Derivativos agrícolas. São Paulo: Globo, 2010. 352 p. (Livros de Valor).

FERRÃO, R. G. et al. Cultivares de café conilon. In: FERRÃO, R. G. et al. (Ed.). Café conilon. Vitória: Incaper, 2007. p. 203-225.

FERREIRA, M. D. P. et al. Relações dos preços no complexo agroindustrial de café no Brasil. In: SIMPÓSIO DE PESQUISA DOS CAFÉS DO BRASIL, 7., 2011, Araxá. Anais... Brasília: Embrapa Café: CBP\&D Café, 2011. CD-ROM.

HALL, P. A.; TAYLOR, R. C. R. Political science and the three new institutionalism. Political Studies, v. 44, n. 5, p. 936-957, 1996. http://dx.doi. org/10.1111/j.1467-9248.1996.tb00343.x

HELLEBUSCH, S. J. Don't read research by the numbers. Marketing News, v. 34, n. 19, p. 25, 2000.

HORA, H. R. M. da; MONTEIRO, G. T. R.; ARICA, J. Confiabilidade em questionários para qualidade: um estudo com o coeficiente alfa de Cronbach. Produto \& Produção, v. 11, n. 2, p. 85-103, 2010.

MARCH, J. G.; OLSE, J. P. El nuevo institucionalismo: factores organizativos de la vida política. Zona Abierta, n. 63-64, p. 1-44, 1993.

MARCONI, M. A.; LAKATOS, E. M. Técnicas de pesquisa. 7. ed. São Paulo: Atlas, 2008. 277 p.

MARTINS, A. L. História do café. 1. ed. São Paulo: Contexto, 2008. 320 p.

MATIELLO, J. B. O café: do cultivo ao consumo. São Paulo: Globo, 1991. 320 p. (Coleção do Agricultor: Grãos).

MÍGUEZ, G. C. Nuevo Institucionalismo em ciencia política, institucionalismo de elección racional y análisis político de costes de transacción: una primera aproximación. Revista de Investigaciones Políticas y Sociológicas, v. 6, n. 2, p. 9-27, 2007.

MINEO, J. C. F. Estudo sobre a possibilidade de redução do risco de preço de commodities agrícolas via mercado de futuros no Brasil. 2010. 78 f. Dissertação (Mestrado 
em Ciências Sociais Aplicadas)-Universidade Federal do Paraná, Curitiba, 2010.

NISHIJIMA, M.; SAES, M. S. M.; POSTALI, F. A. S. Análise de concorrência no mercado mundial de café verde. Revista de Economia e Sociologia Rural, v. 50, n. 1, p. 69-82, 2012. http://dx.doi.org/10.1590/ S0103-20032012000100004

NOGUEIRA, F. T. P.; AGUIAR, D. R. D. Efeitos da desregulamentação na extensão e no grau de integração do mercado brasileiro de café. Revista de Economia, v. 37, n. 3, p. 21-46, 2011.

PENICK, M. A. The development and current state of derivatives markets. In: KOLB, R. W.; OVERDAHL, J. A. (Ed.). Financial derivatives: pricing and risk management. New Jersey: John Wiley \& Sons, 2009. p. 233-247. (Kolb Series in Finance).

PETERS, B. G. Institutional theory in political science: the 'new institutionalism'. 2. ed. Londres: Continuum, 2005. 195 p.

SANTOS, C. M. et al. Mercado futuro de café: um estudo de caso. Registro Contábil, v. 3, n. 1, p. 62-84, 2012.
SCOTT, W. R. Institutions and organizations. 2. ed. Thousand Oaks: Sage, 2001. 255 p.

SKINNER, D.; TAGG, C.; HOLLOWAY, J. Managers and research: the pros and cons of qualitative approaches. Management Learning, v. 31, n. 2, p. 163-179, 2000. http://dx.doi.org/10.1177/1350507600312002

TOLEDO, J. C. de. Gestão da qualidade na agroindústria. In: BATALHA, M. O. (Org.). Gestão agroindustrial. 2. ed. São Paulo: Atlas, 2001. p. 465-517. (v. 1).

WILLIAMSON, O. E. The economic institutions of capitalism: firms, markets, relational contracting. Nova York: Free Press, 1985. 450 p.

ZYLBERSZTAJN, D. Papel dos contratos na coordenação agro-industrial: um olhar além dos mercados. Revista de Economia e Sociologia Rural, v. 43, n. 3, p. 385-420, 2005. http://dx.doi.org/10.1590/ S0103-20032005000300001

ZYLBERSZTAJN, D.; FARINA, E. M. M. Q.; SANTOS, R. C. O sistema agroindustrial do café: um estudo da organização do agribusiness do café visto como a chave da competitividade. Porto Alegre: Ortiz, 1993. 278 p. 